\title{
The 5-lipoxygenase pathway: oxidative and inflammatory contributions to the Alzheimer's disease phenotype
}

\author{
Yash B. Joshi and Domenico Praticò * \\ Department of Pharmacology and Center for Translational Medicine, Temple University School of Medicine, Philadelphia, PA, USA
}

\section{Edited by:}

Victoria Campos, Instituto Nacional de Neurologia y Neurocirugia,

Mexico

\section{Reviewed by:}

Muzamil Ahmad, Indian Institute of Integrative Medicine, India

Luigi Iuliano, Sapienza University of Rome, Italy

\section{${ }^{*}$ Correspondence:}

Domenico Praticò, Department of Pharmacology and Center for Translational Medicine, Temple University School of Medicine, 947 Medical Education and Research Building, 3500 North Broad Street, Philadelphia, PA 19140, USA e-mail: praticod@temple.edu
Alzheimer's disease (AD) is the most common, and, arguably, one of the most-well studied, neurodegenerative conditions. Several decades of investigation have revealed that amyloid- $\beta$ and tau proteins are critical pathological players in this condition. Genetic analyses have revealed specific mutations in the cellular machinery that produces amyloid- $\beta$, but these mutations are found in only a small fraction of patients with the earlyonset variant of $A D$. In addition to development of amyloid- $\beta$ and tau pathology, oxidative damage and inflammation are consistently found in the brains of these patients. The 5lipoxygenase protein enzyme (5LO) and its downstream leukotriene metabolites have long been known to be important modulators of oxidation and inflammation in other disease states. Recent in vivo evidence using murine knock-out models has implicated the 5LO pathway, which also requires the $5 \mathrm{LO}$ activating protein (FLAP), in the molecular pathology of $A D$, including the metabolism of amyloid- $\beta$ and tau. In this manuscript, we will provide an overview of 5LO and FLAP, discussing their involvement in biochemical pathways relevant to $A D$ pathogenesis. We will also discuss how the $5 \mathrm{LO}$ pathway contributes to the molecular and behavioral insults seen in AD and provide an assessment of how targeting these proteins could lead to therapeutics relevant not only for $A D$, but also other related neurodegenerative conditions.

Keywords: Alzheimer's disease, amyloid beta, tau, synapse, memory, 5-lipoxygenase, oxidative stress, neuroinflammation

\section{ALZHEIMER's DISEASE: BACKGROUND}

Alzheimer's disease (AD) is the most common aging-associated neurodegenerative condition with dementia, marked by profound and irreversible memory impairment and cognitive deficits. The total number of individuals with $\mathrm{AD}$ worldwide is estimated to be over 35 million with a predicted estimated annual economic burden of $\$ 600$ billion USD (Alzheimer's Association, 2014). The vast majority of $\mathrm{AD}$ cases are sporadic, without a clear genetic component, and symptoms of AD typically declare themselves after the age of 65 , with $11 \%$ of those 65 and older and $32 \%$ of 85 and older showing signs of AD (source: Alzheimer's Association). Current population demographics suggest that those aged 65 and older will increase from $13 \%$ now to $20 \%$ of total population in 2030, making the future burden of $\mathrm{AD}$ a tremendous public health challenge. In stark contrast to the looming public health challenge of $\mathrm{AD}$, current therapeutic options for $\mathrm{AD}$ are limited. Although a plethora of agents are currently being investigated in phase II and phase III trials, currently approved medications include several acetylcholinesterase inhibitors and N-methyl Daspartate (NMDA) antagonists, which do little to modify disease course (Caraci et al., 2013; Tan et al., 2014). Given the confluence of an increased burden of $\mathrm{AD}$ in the near-future to health systems globally and a lack of approved therapeutic targets, investigation of targets that address multiple different facets of $\mathrm{AD}$ pathophysiology must be actively sought to help address this problem. Below we will give an overview of some of the molecular insults associated with $\mathrm{AD}$, and discuss how the 5-lipoxygenase (5LO) enzyme presents a novel molecular pathway that is an attractive target for $\mathrm{AD}$ therapy.

\section{A $\beta$ AND tau IN ALZHEIMER's DISEASE}

Through extensive clinical and molecular work over the past several decades, the biochemical pathways that lead to $\mathrm{AD}$ pathology have been well characterized. The cardinal pathologies observed in $\mathrm{AD}$ are the extracellular deposits of amyloid- $\beta$ protein $(A \beta)$ known as $A \beta$ plaques, and intracellular accumulations of the hyperphosphorylated microtubule-associated tau protein known as neurofibrillary tangles (Iqbal et al., 2010; Holtzman et al., 2011). Current dogma presumes $A \beta$ as the upstream molecular initiator in $\mathrm{AD}$ based on evidence that mutations in the $\mathrm{A} \beta$ precursor protein (APP) and presenilins, main components of the pathways that cleave it to produce $\mathrm{A} \beta$ peptides, are found in early-onset, familial variants of $\mathrm{AD}$. Additionally, patients with Down's syndrome, in which there is an additional chromosome 21, the locus of the APP gene, have significantly increased rates of $\mathrm{AD}$ when compared with the general population (Wilcock and Griffin, 2013). However, more recent clinical data have also found mutations in the APP gene that are protective and reduce AD risk (Jonsson et al., 2012, 2013). 
Amyloid- $\beta$ peptide is formed by the sequential cleavage of APP by the $\beta$-secretase ( $\beta$ APP cleavage enzyme, BACE 1 ) and the $\gamma$-secretase complex (composed of the nicastrin, presenillin, PS1), anterior-pharynx defective-1 protein [APH-1], and presenillin enhancer protein [Pen-2], as shown in Figure 1. While APP may be cleaved by $\alpha$-secretase and then $\gamma$-secretase to produce nonamyloidogenic products, the $A \beta$ producing pathway is thought to be priviledged in $\mathrm{AD}$. Generation of higher amounts and subsequent aggregation of $A \beta$ peptide through the sequential $\beta$ and $\gamma$-secretase cleavages is thought to lead to soluble oligomers, followed by longer fibrils, and finally insoluble plaques, which are found abundantly in the vast majority of AD patients on autopsy. Although insoluble plaques have been found in the brains of patients without $\mathrm{AD}$, current thinking is that low- $n \mathrm{~A} \beta$ oligomers perpetuate the brunt of molecular insults in $\mathrm{AD}$ rather than insoluble plaques per se (Ono and Yamada, 2011).

The hyperphosphorylation of the microtubule-associated tau protein also contributes to the molecular damage in AD. Tau is thought to be important in neuronal ultrastructure and axonal transport, both critical to overall neuron function and signaling (Iqbal et al., 2010). Upon hyperphosphorylation, tau loses affinity for microtubules, dissociating from them, and begins to aggregate, eventually precipitating inside neuronal cells, as shown in Figure 2. While $A \beta$ is hypothesized to be the initiating event, cortical burden of neurofibrillary tau tangles correlates with dementia severity much more robustly (Oddo et al., 2006; Nelson et al.,

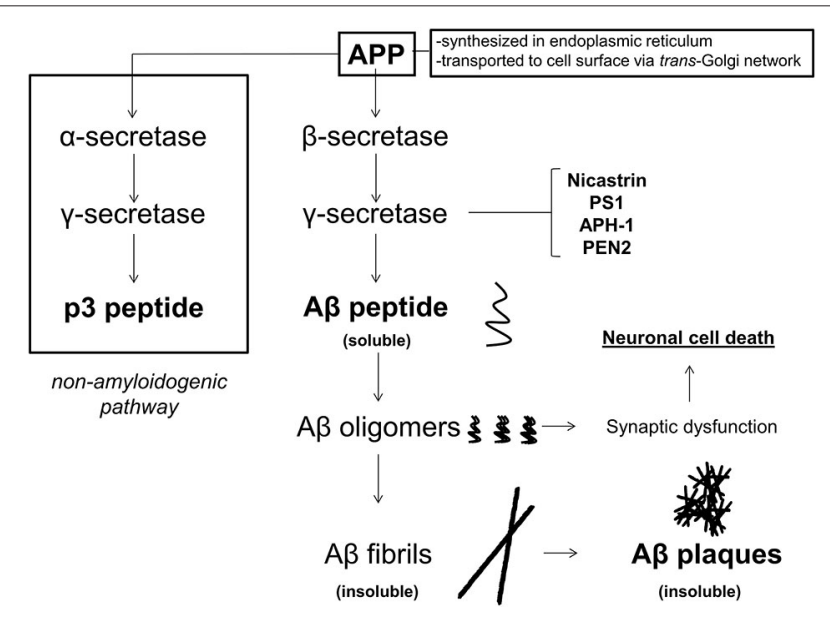

FIGURE 1 | APP metabolism in Alzheimer's disease (AD). Amyloid $\beta$ precursor protein (APP) is synthesized in the endoplasmic reticulum and transported to the cell surface through endosomes via the trans-Golgi network. At the cell membrane, APP may undergo either non-amyloidogenic processing or pro-amyloidogenic processing. If APP undergoes non-amyloidogenic processing, it is first cleaved by the $\alpha$-secretase, and then the $\gamma$-secretase to produce $\mathrm{p} 3$ peptide, which does not form amyloid deposits. If APP is cleaved by $\beta$-, and then $\gamma$-secretase (composed of nicastrin, presenilin 1 [PS1], anterior pharynx defective-1 protein $[A P H-1]$, and presenilin enhancer $2[$ PEN2]), then $A \beta$ peptides are produced. Amyloid- $\beta$ peptides form oligomers, and then fibrils, which become insoluble, and eventually deposit into $A \beta$ plaques. While initially it was thought that $A \beta$ plaques were the causal pathology in $A D$, soluble low-n oligomers are currently thought to play the initiating role in synaptic dysfunction and neuronal cell death.
2007). Normal tau protein phosphorylation status is generally thought to be maintained by the relative balance of tau-specific kinases(s), which would add phosphate, and phosphatase(s), which would remove phosphate. At present, cyclin-dependent kinase 5 and glycogen synthase kinase 3 beta represent two such tau kinases that have been found to be abnormally functional in the brains of $\mathrm{AD}$ patients, and therefore of functional importance (Hanger et al., 1992; Baumann et al., 1993; Pei et al., 1999).

Although the specific mechanisms from disruption of normal functioning of both $\mathrm{A} \beta$ and tau to $\mathrm{AD}$ symptomatology remains unclear, both have been associated with oxidative stress and inflammation found in the brains of AD patients.

\section{OXIDATIVE STRESS AND INFLAMMATION IN ALZHEIMER'S DISEASE}

Balance of oxidation and reduction is critical to appropriate cellar function and results from the interplay of mechanisms that produce pro-oxidant molecules and those processes that detoxify them. The brain receives an overwhelming proportion of total body blood flow (i.e., oxygen) and glucose when adjusted for its weight, and in neurons, this relatively high oxygen and glucose requirement is directed towards energy generation (i.e., ATP production) and oxidative phosphorylation in mitochondria (Scheinberg and Stead, 1949; Smith et al., 2007). The vast majority of oxidative species (predominantly reactive oxygen species such as superoxide anions, hydroxyl radicals and hydrogen peroxide) produced by this metabolism is detoxified by antioxidant vitamins (e.g., vitamin C, and E) as well as superoxide dismutase, catalase and glutathione peroxidase (Adibhatla and Hatcher, 2010). A basal level of oxidants contributes to appropriate cellular signaling and modulates cell function but elevated levels of reactive oxygen species leads to oxidation and irreversible modification of proteins, lipids and nucleic acids which ultimately result in the disruption of their regular function (Ray et al., 2012). Interestingly, consistent evidence supports the hypothesis that a progressive accumulation of oxidative stress damage to important cellular molecules is a fundamental mechanism involved in the process of aging, which is the strongest risk factor for developing sporadic AD (Jacob et al., 2013).

In $\mathrm{AD}$, oxidative modifications of proteins, lipids, DNA in the brain have been repeatedly found. Thus several studies have shown the presence of DNA and RNA oxidation products such as 8-oxo-2'-deoxyguanosine (8-oxo-dG) and 8-dihydro- $2^{\prime}$ guanosine $(8 \mathrm{OH})$ in $\mathrm{AD}$ brains, and lipid peroxidation products such as F2-isoprostanes and various reactive aldehydes have been reported in not only in $\mathrm{AD}$ brains but also in patient cerebrospinal fluid of patients with a clinical diagnosis of AD (de Leon et al., 2007; Sutherland et al., 2013). Although the precise mechanism of oxidation stress in $\mathrm{AD}$ remains elusive, the sulfur atom of methionine 35 in $\mathrm{A} \beta$ peptide has been shown to produce free radicals (Butterfield et al., 2013). Replacement of methionine to cysteine reduced oxidative damage in model organisms such as C. elegans, and substitution of sulfur with a methylene moiety reduces oxidation in vitro of the A $\beta$ peptide (Yatin et al., 1999; Dai et al., 2007). Although clinical trials have not yet found a meaningful disease-modifying effect of antioxidant agents in the 

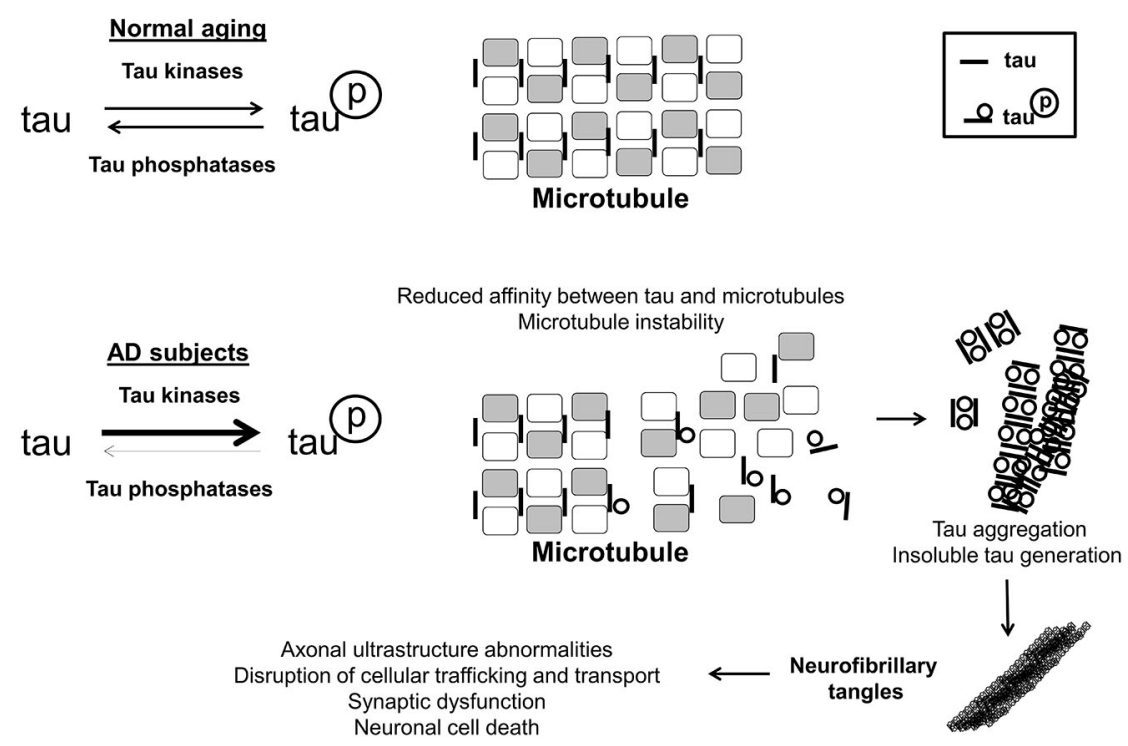

FIGURE 2 | Tau phosphorylation in AD. In the brains of aged, disease-free control subjects, tau is associated with, and has affinity for microtubules, stabilizing them, and promoting normal axonal functioning. Tau may be phosphorylated and de-phosphorylated, with phosphorylation altering its microtubule affinity and stabilizing function, and this is maintained through an interplay of tau-associated kinases and phosphatases. In the brains of AD subjects, tau becomes hyperphosphorylated by means of relatively greater net tau kinase activity/reduced phosphatase activity. Hyperphosphorylated tau has a much lower affinity for microtubules, resulting in disruption of appropriate microtubule structure. Additionally hyperphosphorylated tau aggregates together, eventually generating insoluble tau species which eventually form neurofibrillary tangles intracellularly. As a result of neurofibrillary tangle formation, cellular trafficking and transport is perturbed, leading to cell death and synaptic dysfunction. treatment of $\mathrm{AD}$, many studies have founds significant association between diets rich in antioxidants and lower risk of AD-risk (Pocernich et al., 2011).

Besides oxidative stress damage, altered inflammatory reactions are strongly associated with $\mathrm{AD}$ pathology and cognitive dysfunction. The dysregulation of inflammatory cytokines as well as immune cells (i.e., microglia and astrocytes) activation in AD brains has been well-documented. Microglia have some ability to clear $\mathrm{A} \beta$, but are unable to effectively phagocytate high concentrations (or insoluble conformations) of it resulting in aberrantly activated microglia that associate with both $\mathrm{A} \beta$ plaques and neurofibrillary tangles (Hickman et al., 2008; Johnston et al., 2011; D'Andrea et al., 2004; Krabbe et al., 2013; Morales et al., 2013). Astrocytes can be directly stimulated by $A \beta$ to secrete pro-inflammatory molecules, and evidence is growing that they have the ability to produce $A \beta$ peptides themselves (Blasko et al., 2000; Wang et al., 2011a; Jo et al., 2014). Microgliosis and astrocytosis follow deposition of $A \beta$ plaques and neurofibrillary tangles as shown by immunohistochemistry, and have been shown to precede neuronal loss (Sheng et al., 1997a,b; Sheffield et al., 2000; Wright et al., 2013). Resulting directly from immune cell activation, $\mathrm{AD}$ brains also have higher tissue levels of cytokines, including various interleukins (IL) such as IL- $1 \beta$, tumor necrosis factor $\alpha(\mathrm{TNF} \alpha)$, and interferon $\gamma(\operatorname{IFN} \gamma)$, all independently-linked to increased production of $\mathrm{A} \beta$ and tau phosphorylation (Zilka et al., 2012).
Despite this compelling evidence, prospective clinical trials targeting oxidative stress and inflammation have previously not found clear and incontrovertible disease-modifying effects on the progression of $\mathrm{AD}$. With regard to oxidation, the largest prospective clinical trials have tested combinations of the monoamine oxidase inhibitor, selegiline and alpha-tocopherol (i.e., vitamin E) or the cholinesterase inhibitor, donepezil and alpha-tocopherol, either in patients with severe disease or in the prodromal stage, in those with mild cognitive impairment (Sano et al., 1997; Petersen et al., 2005). In these studies, no difference was found between antioxidant-treated groups and controls in terms of disease progression or on cognitive assessment at the end of intervention. Other studies using a variety of antioxidants such as resveratrol and curcumin, among others, have noted either no benefit, or benefit with limited effect sizes in small cohorts (for an excellent review see Mecocci and Polidori, 2012). Recently, the Trial of Vitamin E and Memantine in Alzheimer's Disease (TEAM-AD) has reported reduction in functional cognitive decline in those receiving alpha-tocopherol compared to placebo (Dysken et al., 2014). However, these results have been criticized due to the relatively high dose of vitamin $\mathrm{E}$ used, and the fact memantine alone or in combination with vitamin $\mathrm{E}$ did not produce similar protective effects (Corbett and Ballard, 2014).

The earliest anti-inflammatory strategies in $\mathrm{AD}$ resulted from data showing reduced $\mathrm{AD}$ incidence in patients with rheumatoid arthritis, who have a high exposure to non-steroidal 
anti-inflammatory agents (McGeer and Rogers, 1992; Stewart et al., 1997). This finding was reproduced in many population studies (for a review, see McGeer and McGeer, 2013). However, placebo-controlled trials for $\mathrm{AD}$ using anti-inflammatory agents showed little benefit and significant adverse effects leading to subject dropout, although it is to be noted that the majority of these trials used a relatively short treatment window before trial termination or cessation (McGeer et al., 1996). Despite these trial failures, new data indicating mutations in Triggering receptor expressed on myeloid cells 2 gene (TREM2), which encodes a membrane protein found on immune cells, confers significant risk in the development of $\mathrm{AD}$, has reinvigorated interest in an anti-inflammatory strategy in $\mathrm{AD}$ (Jonsson et al., 2013).

In recent years, mounting evidence has indicated that $\mathrm{A} \beta$ and tau pathologies begin depositing and impair neuronal function long before symptoms are manifest. Give this insight it is unlikely that recent and previously conducted clinical trials can adequately address the true effectiveness of anti-oxidant and antiinflammatory agents. Additionally, the multifactorial nature of the molecular insults in $\mathrm{AD}$ make it likely that a strategy that addresses not only pathological $\mathrm{A} \beta$ and tau accumulation, but also oxidation and inflammation would have the best chance of success.

\section{THE 5-LIPOXYGENASE PATHWAY}

The 5LO inserts molecular oxygen into the 5th carbon of free or esterified fatty acids, most notably arachidonic acid. In order to carry out the reaction, 5LO also requires 5LO activating protein, FLAP, which presents the substrate for enzymatic action (for a complete review on 5LO biology, see Rådmark and Samuelsson, 2010). Immediate products of 5LO include unstable 5-hydroperoxyeicosatetraenoic acid which is either reduced to 5-hydroxyeicosatetraenoic acid or leukotriene $\mathrm{A}_{4}\left(\mathrm{LTA}_{4}\right)$. Depending on the cellular milieu, LTA4 can be metabolized either to leukotriene $\mathrm{B}_{4}$ or $\mathrm{C}_{4}\left(\mathrm{LTB}_{4}\right.$ or $\left.\mathrm{LTC}_{4}\right)$, with $\mathrm{LTC}_{4}$ further being metabolized to $\mathrm{LTD}_{4}$ and $\mathrm{LTE}_{4}$ (Bishayee and Khuda-Bukhsh, 2013), as shown in Figure 3.

5-lipoxygenase is found in vasculature, in endothelial cells, as well as throughout the central nervous system, in both neuron and glia (Chu and Praticò, 2009). Interestingly, 5LO expression and its metabolites increase with age in both animal models as well as human subjects. 5-lipoxygenase protein levels are particularly enriched in both cortex as well as hippocampus, areas known to be particularly vulnerable in neurodegeneration, and in AD in particular (Lammers et al., 1996; Chinnici et al., 2007). 5-lipoxygenase promotes lipid peroxidation in vitro as well as in brain tissue (Czubowicz et al., 2010; Czapski et al., 2012). Leukotrienes, metabolic products of 5LO activation, initiate immune cell chemotaxis and are critical molecular players in the inflammatory pathophysiology of asthma and allergy (Kanaoka and Boyce, 2014).

\section{LO, FLAP AND THE ALZHEIMER's DISEASE PHENOTYPE}

Post-mortem studies have initially shown that 5LO is increased in AD (Firuzi et al., 2008; Ikonomovic et al., 2008). A small pilot study in humans has linked 5LO gene polymorphisms to

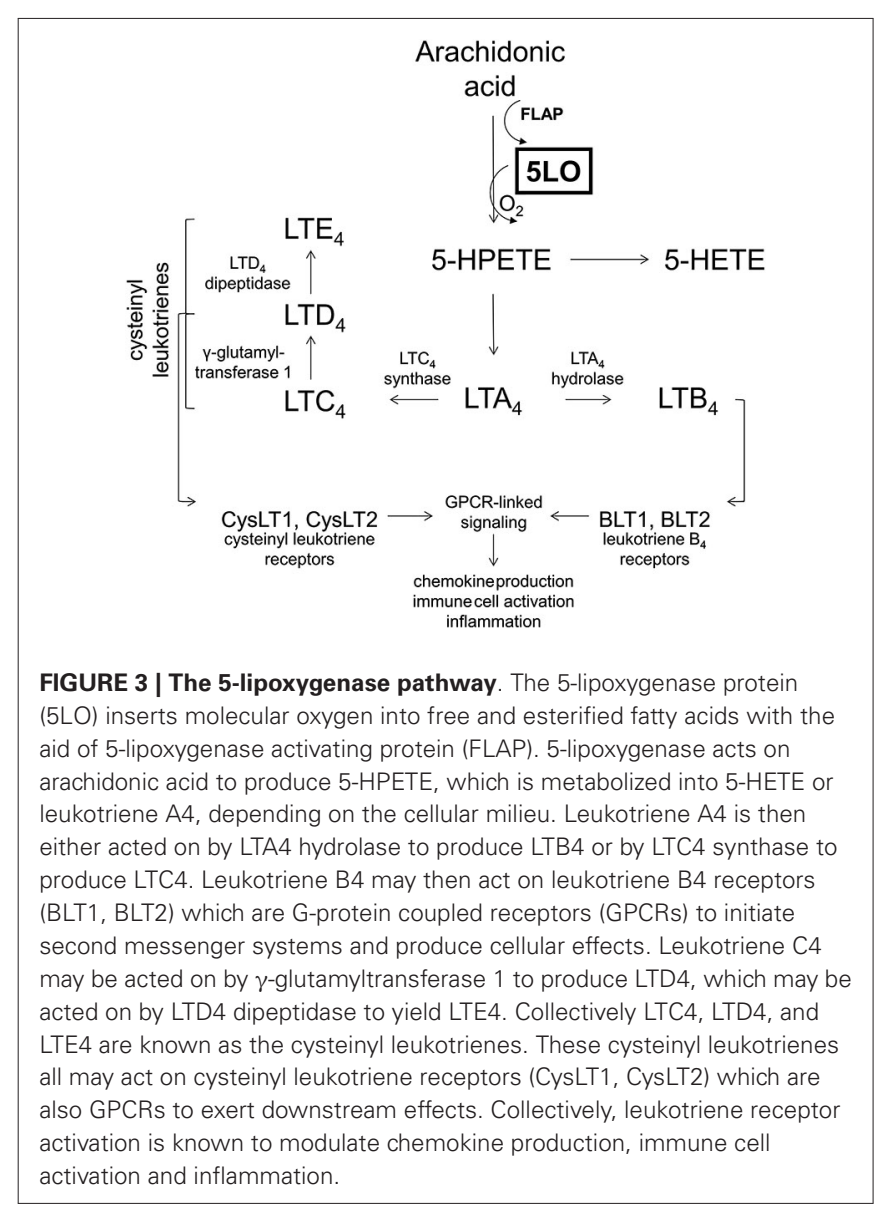

early- and late-onset $\mathrm{AD}$, although large-scale population studies are yet to confirm these findings (Qu et al., 2001). In neuro2A cells harboring the Swedish APP mutation, knockout of 5LO reduces reduces their ability to produce and release soluble $A \beta$ levels (Chu and Praticò, 2011a). This effect is due to reduced activity of $\gamma$-secretase, with 5LO knockout lowering steady-state expression of nicastrin, PS1, APH-1 and Pen-2 proteins without affecting either APP, the $\beta$-secretase or $\alpha$-secretase pathway. On the other hand, overexpression of 5LO produces the opposite effect in vitro: $\mathrm{A} \beta$ levels are elevated, and associated with increased protein and mRNA levels of all $\gamma$-secretase proteins. While several molecules have been linked to the regulation of $\gamma$-secretase mRNA level, 5LO modulation occurs through the phosphorylation of cyclic adenosine response element-binding protein, CREB. Pharmacological inhibition of $5 \mathrm{LO}$ also reproduces 5LO knockout effects (Chu and Praticò, 2011b). Although $\gamma$-secretase produces $A \beta$ peptides, which are pathologic in $A D$, it is also involved in the processing of Notch, a protein critical for neuronal functioning and differentiation (Imbimbo and Giardina, 2011). Clinical trials investigating $\gamma$-secretase inhibitors for use in $\mathrm{AD}$ have to date been largely unsuccessful because they are hypothesized to have altered Notch signaling as well as $\mathrm{A} \beta$ production (Doody et al., 2013). Fortunately, with 5LO modulation, $\gamma$ secretase-dependent Notch production is unperturbed, making any future and potential use of this class of 
drug a feasible alternative to calssical $\gamma$-secretase inhibitors. By directly controlling the substrate availability for 5LO, FLAP modulation similarly affects $\mathrm{A} \beta$ production with FLAP knockout and pharmacological inhibition reducing $A \beta$ through a CREB-mediated $\gamma$-secretase down-regulation (Chu and Praticò, 2012). In vitro data in neuronal cells have been reproduced in mouse models of AD-like amyloidosis with similar effects of $5 \mathrm{LO}$ and FLAP on $\mathrm{A} \beta$, which includes immunohistochemical evidence of plaque reduction upon 5LO or FLAP knockout (Giannopoulos et al., 2013, 2014). Recently, these data have also been reproduced in TgCRND8 animals, with reduction found in amyloid-associated angiopathy upon administration of MK886, an inhibitor of FLAP (Hawkes et al., 2014). Intriguingly, leukotriene metabolites of 5LO have also been reported to increase $\beta$ - and $\gamma$-secretase-mediated generation (Wang et al., 2013).

In addition to $\mathrm{A} \beta, 5 \mathrm{LO}$ and FLAP also modulate tau phosphorylation. In cells overexpressing 5LO, tau is hyperphosphorylated, generating both early-stage, as well as advanced-stage tau phosphoepitopes (Chu et al., 2013). Beyond tau phosphorylation, 5LO overexpression results in production of paired helical filaments of tau, precursors to insoluble tau deposition and neurofibrillary tangle formation. Knockout or inhibition of 5LO or FLAP produces results in amelioration of tau hyperphosphorylation (Chu and Praticò, 2013; Chu et al., 2013). Both in vivo in murine models and in vitro, 5LO pathway changes are mediated by 5LO and FLAP influence on cyclin-dependent kinase 5 activity (Chu and Praticò, 2013). As mentioned previously, abnormalities in $\mathrm{A} \beta$ metabolism are presumed to be upstream of tau phosphorylation but 5LO effects on tau phosphorylation seem to be independent of $A \beta$. In a series of in vitro experiments, $\gamma$-secretase blockade in the presence of 5LO overexpression did not prevent 5LO-mediated hyperphosphorylation of tau (Chu et al., 2013). These in vitro results have also been corroborated in not only a mouse model of amyloidosis such as the Tg2576 mouse, but also a model with both $A \beta$ and tau pathology such as the 3xTg mouse (Chu et al., 2012b, 2013).

Beyond neuropathology, knockout of 5LO or FLAP mitigates age-dependent $\mathrm{AD}$ learning and memory insults seen in two models of AD. In both Tg2576 and 3xTg mice, 5LO knockout or inhibition is associated with improvements in learning and memory over baseline in fear conditioning paradigms while overexpression of $5 \mathrm{LO}$ is associated with greater cognitive insult (Chu and Praticò, 2011a; Chu et al., 2012a,b; Giannopoulos et al., 2013, 2014). Knockout or inhibition of 5LO and FLAP also ameliorates markers of synaptic protein pathology and restores hippocampal long-term potentiation to wild-type levels (Giannopoulos et al., 2013, 2014). Even in aged transgenic mice, when significant $\mathrm{AD}$ pathology has been deposited, targeting the 5LO pathway appears to improve the overall AD-like phenotype (Di Meco et al., 2014).

\section{LO, FLAP AND ALZHEIMER's DISEASE-ASSOCIATED OXIDATION AND INFLAMMATION}

While 5LO and FLAP appear to reduce the cardinal pathologies in $\mathrm{AD}$, they also act on $\mathrm{AD}$ pathology-induced oxidative and inflammatory insult.
In cultured rat hippocampal neurons, 5LO pathway inhibition results in reduced $A \beta$-induced reactive oxygen species generation and subsequent calcium dysregulation in a concentrationdependent manner (Goodman et al., 1994). 5-lipoxygenase pathway inhibition also protects against glutamate-induced excitotoxicity in vivo in rats, particularly in aged animals ( $\mathrm{Uz}$ et al., 1998). In other in vitro systems, 5LO overexpression does not by itself lead to oxidative damage, but when overexpressed in the presence of $A \beta$ peptides, reduces glutathione peroxidase and catalase levels (Wang et al., 2011b). 5-lipoxygenase pathway inhibition by the pyrazole CNB-001, a 5LO-specific inhibitor, protects against endoplasmic reticulum dysfunction and proteasome toxicity induced by $\mathrm{A} \beta$ both in cultured neurons as well as in vivo (Valera et al., 2013). Interestingly, inhibition of FLAP is not sufficient to protect against $\mathrm{A} \beta$ oxidative toxicity in vitro, which suggests that even when $5 \mathrm{LO}$ is decoupled from $\mathrm{A} \beta$ metabolism, its ability to insert molecular oxygen is preserved, retaining pro-oxidative properties in a leukotriene-independent fashion. However, this phenomenon is otherwise not well described or replicated in neurons and requires further scrutiny and exploration. On the other hand, leukotriene blockade has been linked to reduction in cognitive deficits induced by traumatic brain injury in rats, a source of oxidative stress, and a well-known risk factor for AD (Corser-Jensen et al., 2014).

Besides oxidation, both 5LO and FLAP are active players in the neuroinflammation found in AD. Disruption of the 5LO pathway, either genetically or pharmacologically, reduces not only microglia, but also astrocytosis in the brains of $\mathrm{AD}$ animals, seen on immunohistochemical analyses (Chu and Praticò, 2012). Moreover, with 5LO/FLAP disruption there is an associated reduction in pro-inflammatory cytokine levels. An argument can be made that reduction in $A \beta$ and tau pathology caused by 5LO/FLAP inhibition independently predisposes $\mathrm{AD}$ transgenic animals to have reduced neuroinflammation at baseline. While this may be true to some extent, chronic lipopolysaccharide administration in $\mathrm{AD}$ animals lacking 5LO increases steady-state levels of $\gamma$-secretase machinery and tau phosphorylation but does not change baseline microgliosis, astrocytosis, or brain levels of inflammatory cytokines (Joshi et al., 2014). This line of data suggests that the $5 \mathrm{LO}$ system's contribution to the neuroinflammation does not depend exclusively on $A \beta$ or tau.

\section{IMPLICATIONS FOR ALZHEIMER's DISEASE THERAPY AND BEYOND}

Although several clinical trials have targeted $A \beta$ specifically, increasingly, their failures have lead commentators to reevaluate not only the time course of intervention in $\mathrm{AD}$, but also the selected therapeutic targets. While tau is increasingly being recognized as a viable target, and anti-oxidant and anti-inflammatory strategies are frequently employed in studies to modify disease course, no agent to date has been employed that independently modulates $\mathrm{A} \beta$ metabolism, tau phosphorylation, oxidation and inflammation. Although more work must be done to dissect the mechanisms of 5LO action in model systems more advanced than mice before considering it as a viable target, 5LO pathway suppression has the added benefit of being safe in other 
chronic conditions such as asthma (i.e., Zileuton, Monteleukast). Beyond AD, 5LO pathway targeting may also be useful in other dementias and related conditions including: non-AD amyloidoses (i.e., cerebral amyloid angiopathy), tauopathies (e.g., frontotemporal dementia, chronic traumatic encephalopathy, progressive supranuclear palsy), oxidation-linked nervous system disorders (i.e., amyotrophic lateral sclerosis) and inflammation-centered disease processes (i.e., multiple sclerosis). Further work exploring the 5LO system would undoubtedly shed more light on the molecular pathways common to neurodegeneration and represent a novel and promising platform for future drug development.

\section{ACKNOWLEDGMENTS}

The work form the author's lab described in the present article has been in part supported by grants for the National Institute of Health, the Alzheimer's Association and the Alzheimer's Art Quilt Initiative.

\section{REFERENCES}

Adibhatla, R. M., and Hatcher, J. F. (2010). Lipid oxidation and peroxidation in CNS health and disease: from molecular mechanisms to therapeutic opportunities. Antiox. Redox. Signal. 12, 125-169. doi: 10.1089/ars.2009.2668

Alzheimer's Association. (2014). Alzheimer's disease facts and figures. Alzheimer's \& Dementia 10. Available online at: http://www.alz.org/downloads/Facts_ Figures_2014.pdf. Accessed on October 2, 2014.

Baumann, K., Mandelkow, E. M., Biernat, J., Piwnica-Worms, H., and Mandelkow, E. (1993). Abnormal Alzheimer-like phosphorylation of tau-protein by cyclindependent kinases cdk2 and cdk5. FEBS Lett. 336, 417-424. doi: 10.1016/00145793(93)80849-p

Bishayee, K., and Khuda-Bukhsh, A. R. (2013). 5-lipoxygenase antagonist therapy: a new approach towards targeted cancer chemotherapy. Acta Biochim. Biophys. Sin. (Shanghai) 45, 709-719. doi: 10.1093/abbs/gmt064

Blasko, I., Veerhuis, R., Stampfer-Kountchev, M., Saurwein-Teissl, M., Eikelenboom, P., and Grubeck-Loebenstein, B. (2000). Costimulatory effects of interferon-gamma and interleukin-1beta or tumor necrosis factor alpha on the synthesis of Abeta1-40 and Abetal-42 by human astrocytes. Neurobiol. Dis. 7, 682-689. doi: 10.1006/nbdi.2000.0321

Butterfield, D. A., Swomley, A. M., and Sultana, R. (2013). Amyloid beta-peptide (1-42)-induced oxidative stress in Alzheimer disease: importance in disease pathogenesis and progression. Antioxid. Redox Signal. 19, 823-835. doi: 10. 1089/ars.2012.5027

Caraci, F., Bosco, P., Legglo, G. M., Malaquarnera, M., Drago, F., Bucolo, C., et al. (2013). Clinical pharmacology of novel anti-Alzheimer disease modifying medications. Curr. Top. Med. Chem. 12, 1853-1863. doi: 10. 2174/15680266113139990141

Chinnici, C. M., Yao, Y., and Pratico, D. (2007). The 5-lipoxygenase enzymatic pathway in the mouse brain: young versus old. Neurobiol. Aging 28, 1457-1462. doi: 10.1016/j.neurobiolaging.2006.06.007

Chu, J., Giannopoulos, P. F., Ceballos-Diaz, C., Golde, T. E., and Pratico, D. (2012a). Adeno-associated virus0mediated brain delivery of 5-lipoxygenase modulates the AD-like phenotype of APP mice. Mol. Neurodegener. 7:1. doi: 10.1186/17501326-7-1

Chu, J., Giannopoulos, P. F., Ceballos-Diaz, C., Golde, T. E., and Praticò, D. (2012b). 5-lipoxygenase gene transfer worsens memory, amyloid and tau brain pathologies in a mouse model of Alzheimer's disease. Ann. Neurol. 72, 442-454. doi: 10.1002/ana.23642

Chu, J., Li, J. G., Ceballos-Diaz, C., Golde, T., and Praticò, D. (2013). The influence of 5-lipoxygenase on Alzheimer's disease-related tau pathology: in vivo and in vitro evidence. Biol. Psychiatry 74, 321-328. doi: 10.1016/j.biopsych.2012. 12.012

Chu, J., and Praticò, D. (2009). The 5-lipoxygenase pathway as a common pathway for pathological brain and vascular aging. Cardiovasc. Psychiatry Neurol. 2009:174657. doi: 10.1155/2009/174657

Chu, J., and Praticò, D. (2011a). Pharmacological blockade of 5-lipoxygenase improves the amyloidotic phenotype of an Alzheimer's disease transgenic mouse model involvement of gamma-secretase. Am. J. Pathol. 178, 1762-1769. doi: 10. 1016/j.ajpath.2010.12.032

Chu, J., and Praticò, D. (2011b). 5-lipoxygenase as an endogenous modulator of amyloid beta formation in vivo. Ann. Neurol. 69, 34-46. doi: 10.1002/ana. 22234

Chu, J., and Praticò, D. (2012). Involvement of 5-lipoxygenase activating protein in the amyloidotic phenotype of an Alzheimer's disease mouse model. J. Neuroinflammation 9:127. doi: 10.1186/1742-2094-9-127

Chu, J., and Praticò, D. (2013). 5-lipoxygenase pharmacological blockade decreases tau phosphorylation in vivo: involvement of the cyclin-dependent kinase-5. Neurobiol. Aging 34, 1549-1554. doi: 10.1016/j.neurobiolaging.2012.12.009

Corbett, A., and Ballard, C. (2014). The value of vitamin E as a treatment for Alzheimer's disease remains unproven despite functional improvement, due to a lack of established effect on cognition or other outcomes from RCTs. Evid. Based Med. 19:140. doi: 10.1136/eb-2014-101741

Corser-Jensen, C. E., Goodell, D. J., Freund, R. K., Serbedzja, P., Murphy, R. C., and Farias, S. E. (2014). Blocking leukotriene synthesis attenuates the pathophysiology of traumatic brain injury and associated cognitive deficits. Exp. Neurol. 256, 7-16. doi: 10.1016/j.expneurol.2014.03.008

Czapski, G. A., Czubowicz, K., and Strosznajder, R. P. (2012). Evaulation of the antioxidative properties of lipoxygenase inhibitors. Pharmacol. Rep. 64, 11791188. doi: 10.1016/s1734-1140(12)70914-3

Czubowicz, K., Czapski, G. A., Cieślik, M., and Strosznajder, R. P. (2010). Lipoxygenase inhibitors protect brain cortex macromolecules against oxidation evoked by nitrosative stress. Folia Neuropathol. 48, 289-292.

Dai, X. L., Sun, Y. X., and Jiang, Z. F. (2007). Attenuated cytotoxicity but enhanced betafibril of a mutant amyloid beta-peptide with a methionine to cysteine substitution. FEBS Lett. 581, 1269-1274. doi: 10.1016/j.febslet.2007.02.038

D'Andrea, M. R., Cole, G. M., and Ard, M. D. (2004). The microglial phagocytic role with specific plaque types in the Alzheimer's disease brain. Neurobiol. Aging 25, 675-683. doi: 10.1016/j.neurobiolaging.2003.12.026

de Leon, M. J., Mosconi, L., Blennow, K., DeSanti, S., Zinkowski, R., Mehta, P. D., et al. (2007). Imaging and CSF studies in the preclinical diagnosis of Alzheimer's disease. Ann. N Y Acad. Sci. 1097, 114-145. doi: 10.1196/annals.1379.012

Di Meco, A., Lauretti, E., Vagnozzi, A. N., and Praticò, D. (2014). Zileuton restores memory impairments and reverses amyloid and tau pathology in aged Alzheimer's disease mice. Neurobiol. Aging 35, 2458-2464. doi: 10.1016/j. neurobiolaging.2014.05.016

Doody, R. S., Raman, R., Farlow, M., Iwatsubo, T., Vellas, B., Joffe, S., et al. (2013). A phase 3 trial of semagacestat for treatment of Alzheimer's disease. N. Engl. J. Med. 369, 341-350. doi: 10.1056/NEJMoa1210951

Dysken, M. W., Sano, M., Asthana, S., Vertrees, J. E., Pallaki, M., Llorente, M., et al. (2014). Effect of vitamin $\mathrm{E}$ and memantine on functional decline in Alzheimer disease: the TEAM-AD VA cooperative randomized trial. JAMA 311, 33-44. doi: 10.1001/jama.2013.282834

Firuzi, O., Zhuo, J., Chinnici, C. M., Wisniewski, T., and Praticò, D. (2008). 5-lipoxygenase gene disruption reduces amyloid-beta pathology in a mouse model of Alzheimer's disease. FASEB J. 22, 1169-1178. doi: 10.1096/fj.079131.com

Giannopoulos, P. F., Chu, J., Joshi, Y., Sperow, M., Li, J., Kirby, L., et al. (2013). 5lipoxygenase activating protein reduction ameliorates cognitive deficit, synaptic dysfunction, and neuropathology in a mouse model of Alzheimer's disease. Biol. Psychiatry 74, 348-356. doi: 10.1016/j.biopsych.2013.04.009

Giannopoulos, P. F., Chu, J., Joshi, Y. B., Sperow, M., Li, J. G., Kirby, L. G., et al. (2014). Gene knockout of 5-lipoxygenase rescues synaptic dysfunction and improves memory in the triple-transgenic model of Alzheimer's disease. Mol. Psychiatry 19, 511-518. doi: 10.1038/mp.2013.23

Goodman, Y., Steiner, M. R., Steiner, S. M., and Mattson, M. P. (1994). Nordihydroguaiaretic acid protects hippocampal neurons against amyloid $\beta$-peptide toxicity and attenuates free radical and calcium accumulation. Brain Res. 15, 171-176. doi: 10.1016/0006-8993(94)91586-5

Hanger, D. P., Hughes, K., Woodgett, J. R., Brion, J. P., and Anderton, B. H. (1992). Glycogen synthase kinase-3 induces Alzheimer's disease-like phosphorylation of tau: generation of paired helical filament epitopes and neuronal localisation of the kinase. Neurosci. Lett. 147, 58-62. doi: 10.1016/0304-3940(92) 90774-2

Hawkes, C. A., Shaw, J. E., Brown, M., Sampson, A. P., McLaurin, J., and Carare, R. O. (2014). MK886 reduces cerebral amyloid angiopathy severity in TgCRND8 mice. Neurodegener. Dis. 13, 17-23. doi: 10.1159/000351096 
Hickman, S. E., Allison, E. K., and El Khoury, J. (2008). Microglial dysfunction and defective beta-amyloid clearance pathways in aging Alzheimer's disease mice. J. Neurosci. 28, 8354-8360. doi: 10.1523/JNEUROSCI.0616-08.2008

Holtzman, D. M., Morris, J. C., and Goate, A. M. (2011). Alzheimer's disease: the challenge of the second century. Sci. Transl. Med. 3:77sr1. doi: 10. 1126/scitranslmed.3002369

Ikonomovic, M. D., Abrahamson, E. E., Uz, T., Manev, H., and Dekosky, S. T. (2008). Increased 5-lipoxygenase immunoreactivity in the hippocampus of patients with Alzheimer's disease. J. Histochem. Cytochem. 56, 1065-1073. doi: 10.1369/jhc.2008.951855

Imbimbo, B. P., and Giardina, G. A. (2011). $\gamma$-secretase inhibitors and modulators for the treatment of Alzheimer's disease: disappointments and hopes. Curr. Top. Med. Chem. 11, 1555-1570. doi: 10.2174/156802611795860942

Iqbal, K., Liu, F., Gong, C. X., and Grundke-Iqbal, I. (2010). Tau in Alzheimer disease and related tauopathies. Curr. Alzheimer Res. 7, 656-664. doi: 10. 2174/156720510793611592

Jacob, K. D., Noren Hooten, N., Trzeclak, A. R., and Evans, M. K. (2013). Markers of oxidant stress that are clinically relevant in aging and age-related disease. Mech. Aging Dev. 134, 139-157. doi: 10.1016/j.mad.2013.02.008

Jo, W. K., Law, A. C., and Chung, S. K. (2014). The neglected co-star in the dementia drama: the putative roles of astrocytes in the pathogenesis of major neurocognitive disorders. Mol. Psychiatry 19, 159-167. doi: 10.1038/mp. 2013.171

Johnston, H., Boutin, H., and Allan, S. M. (2011). Assessing the contribution of inflammation in models of Alzheimer's disease. Biochem. Soc. Trans. 39, 886890. doi: 10.1042/BST0390886

Jonsson, T., Atwal, J. K., Steinberg, S., Snaedal, J., Jonsson, P. V., Bjornsson, S., et al. (2012). A mutation in APP protects against Alzheimer's disease and age-related cognitive decline. Nature 488, 96-99. doi: 10.1038/nature11283

Jonsson, T., Stefansson, H., Steinberg, S., Jonsdottir, I., Jonsson, P. V., Snaedal, J., et al. (2013). Variant of TREM2 associated with the risk of Alzheimer's disease. N. Engl. J. Med. 368, 107-116. doi: 10.1056/NEJMoa1211103

Joshi, Y. B., Giannopoulos, P. F., Chu, J., and Praticò, D. (2014). Modulation of lipopolysaccharide-induced memory insult, gamma-secretase and neuroinflammation in triple transgenic mice by 5-lipoxygenase. Neurobiol. Aging 35, 1024 1031. doi: 10.1016/j.neurobiolaging.2013.11.016

Kanaoka, Y., and Boyce, J. A. (2014). Cysteinyl leukotrienes and their receptors: emerging concepts. Allergy Asthma Immunol. Res. 6, 288-295. doi: 10.4168/aair. 2014.6.4.288

Krabbe, G., Halle, A., Matyash, V., Rinnenthal, J. L., Eom, G. D., Bernhardt, U., et al. (2013). Functional impairment of microglia coincides with beta-amyloid deposition in mice with Alzheimer-like pathology. PLoS One 8:e60921. doi: 10. 1371/journal.pone.0060921

Lammers, C. H., Schweitzer, P., Facchinetti, P., Arrang, J. M., Madamba, S. G., Siggins, G. R., et al. (1996). Arachidonate 5-lipoxygenase and its activating protein: prominent hippocampal expression and role in somatostatin signaling. J. Neurochem. 66, 147-152. doi: 10.1046/j.1471-4159.1996.660 10147.x

McGeer, P. L., and McGeer, E. G. (2013). The amyloid cascade-inflammatory hypothesis of Alzheimer's disease: implications for therapy. Acta Neuropathol. 126, 479-497. doi: 10.1007/s00401-013-1177-7

McGeer, P. L., and Rogers, J. (1992). Anti-inflammatory agents as a therapeutic approach to Alzheimer's disease. Neurology 42, 447-449. doi: 10.1212/WNL. 42.2.447

McGeer, P. L., Schulzer, M., and McGeer, E. G. (1996). Arthritis and antiinflammatory agents as possible protective factors for Alzheimer's disease: a review of 17 epidemiologic studies. Neurology 47, 425-432. doi: 10.1212/wnl. 47.2.425

Mecocci, P., and Polidori, M. C. (2012). Antioxidant clinical trials in mild cognitive impairment and Alzheimer's disease. Biochim. Biophys. Acta 1822, 631-638. doi: 10.1016/j.bbadis.2011.10.006

Morales, I., Jiménez, J. M., Mancilla, M., and Maccioni, R. B. (2013). Tau oligomers and fibrils induce activation of microglial cells. J. Alzheimer Dis. 37, 849-856. doi: 10.3233/JAD-131843

Nelson, P. T., Jicha, G. A., Schmitt, F. A., Liu, H., Davis, D. G., Mendiondo, M. S., et al. (2007). Clinicopathologic correlations in a large Alzheimer disease center autopsy cohort: neuritic plaques and neurofibrillary tangles "do count" when staging disease severity. J. Neuropathol. Exp. Neurol. 66, 1136-1146. doi: 10. 1097/nen.0b013e31815c5efb
Oddo, S., Caccamo, A., Tran, L., Lambert, M. P., Glabe, C. G., Klein, W. L., et al. (2006). Temporal profile of amyloid-beta(Abeta) oligomerization in an in vivo model of Alzheimer's disease: a link between Abeta and tau pathology. J. Biol. Chem. 281, 1599-1604. doi: 10.1074/jbc.m507892200

Ono, K., and Yamada, M. (2011). Low-n oligomers as therapeutic targets of Alzheimer's disease. J. Neurochem. 117, 19-28. doi: 10.1111/j.1471-4159.2011. 07187.x

Pei, J. J., Braak, E., Braak, H., Grundke-Iqbal, I., Iqbal, K., Winblad, B., et al. (1999). Distribution of active glycogen synthase kinase $3 \beta(\mathrm{GSK}-3 \beta)$ in brans staged for Alzheimer disease neurofibrillary changes. J. Neuropathol. Exp. Neurol. 58, 1010 1019. doi: 10.1097/00005072-199909000-00011

Petersen, R. C., Thomas, R. G., Grundman, D., Bennett, R., Doody, S., Ferris, D., et al. (2005). Vitamin E and donepezil for the treatment of mild cognitive impairment. N. Engl. J. Med. 352, 2379-2388. doi: 10.1056/NEJMoa0 50151

Pocernich, C. B., Lange, M. L., Sultana, R., and Butterfield, D. A. (2011). Nutritional approaches to modulate oxidative stress in Alzheimer's disease. Curr. Alzheimer Res. 8, 452-459. doi: 10.2174/156720511796391908

Qu, T., Manev, R., and Manev, H. (2001). 5-lipoxygenase (5-LOX) promoter polymorphisms in patients with early-onset and late-onset Alzheimer's disease. J. Neuropsychiatry Clin. Neurosci. 13, 304-305. doi: 10.1176/appi.neuropsych.13. 2.304

Rådmark, O., and Samuelsson, B. (2010). Regulation of 5-lipoxygenase, a key enzyme in leukotriene biosynthesis. Biochem. Biophys. Res. Commun. 396, 105110. doi: 10.1016/j.bbrc.2010.02.173

Ray, P. D., Huang, B., and Tsuji, Y. (2012). Reactive oxygen species (ROS) homeostasis and redox regulation in cellular signaling. Cell Signal. 24, 981-990. doi: 10. 1016/j.cellsig.2012.01.008

Sano, M., Ernesto, R. G., Thomas, M. R., Klauber, K., Schafer, M., Grunderson, P., et al. (1997). A controlled trial of selegiline, alpha-tocopherol, or both as treatment for Alzheimer's disease. The Alzheimer's disease cooperative study. N. Engl. J. Med. 336, 1216-1222. doi: 10.1056/nejm1997042433 61704

Scheinberg, P., and Stead, E. A. (1949). The cerebral blood flow in male subjects as measured by the nitrous oxide technique. Normal values for blood flow, oxygen utilization, glucose utilization and peripheral resistance with observations on the effect of tilting and anxiety. J. Clin. Invest. 28, 1163-1171. doi: 10. 1172/jci102150

Sheffield, L. G., Marquis, J. G., and Berman, N. E. (2000). Regional distribution of cortical microglial parallels that of neurofibriallary tangles in Alzheimer's disease. Neurosci. Lett. 285, 165-168. doi: 10.1016/s0304-3940(00) 01037-5

Sheng, J. G., Mrak, R. E., and Griffin, W. S. (1997a). Glial-neuronal interactions in Alzheimer's disease: progressive association of IL-lalpha+ microglia and S100beta+ astrocytes with neurofibrillary tangle stages. J. Neuropathol. Exp. Neurol. 56, 285-290. doi: 10.1097/00005072-199703000-00007

Sheng, J. G., Mrak, R. E., and Griffin, W. S. (1997b). Neuritic plaque evolution in Alzheimer's disease is accompanied by transition of activated microglia from primed to enlarged to phagocytic forms. Acta Neuropathol. 94, 1-5. doi: 10 . 1007/s004010050664

Smith, D. G., Cappai, R., and Barnham, K. J. (2007). The redox chemistry of the Alzheimer's disease amyoid beta peptide. Biochim. Biophys. Acta 8, 1976-1990. doi: 10.1016/j.bbamem.2007.02.002

Stewart, W. F., Kawas, C., Corrada, M., and Metter, E. J. (1997). Risk of Alzheimer's disease and duration of NSAID use. Neurology 48, 626-632. doi: 10.1212/wnl. 48.3.626

Sutherland, G. T., Chami, B., Youssef, P., and Witting, P. K. (2013). Oxidative stress in Alzheimer's disease: primary villain or physiological by-product. Redox Rep. 18, 134-141. doi: 10.1179/1351000213Y.0000000052

Tan, C. C., Yu, J. T., Wang, H. F., Tan, M. S., Meng, X. F., Wang, C., et al. (2014). Efficacy and safety of donepezil, galantamine, rivastigmine and memantine for the treatment of Alzheimer's disease: a systematic review and meta-analysis. J. Alzheimer Dis. 41, 615-631. doi: 10.3233/JAD-132690

Uz, T., Pesold, C., Longone, P., and Manev, H. (1998). Aging-associated upregulation of neuronal 5-lipoxygenase expression: putative role in neuronal vulnerability. FASEB J. 12, 439-449.

Valera, E., Dargusch, R., Maher, P. A., and Schubert, D. (2013). Modulation of 5-lipoxygenase proteotoxicity and Alzheimer's disease. J. Neurosci. 33, 10512 10525. doi: 10.1523/JNEUROSCI.5183-12.2013 
Wang, Y., Li, M., Tang, J., Song, M., Xu, X., Xiong, J., et al. (2011a). Glucocorticoids facilitate astrocytic amyloid- $\beta$ peptide deposition by increased expression of APP and BACE1 and decreasing the expression of amyloid$\beta$-degrading proteases. Endocrinology 152, 2704-2715. doi: 10.1210/en. 2011-0145

Wang, X. Y., Tang, S. S., Hu, M., Long, Y., Li, Y. Q., Liao, M. X., et al. (2013). Leukotriene D4 induces amyloid-beta generation via CysLT(1)R-mediated NFkappaB pathways in primary neurons. Neurochem. Int. 62, 340-347. doi: 10. 1016/j.neuint.2013.01.002

Wang, Z. J., Zhou, B., Mao, W. W., and Yin, M. (2011b). Overexpression of 5-lipoxygenase increases the neuronal vulnerability of PC12 cells to $\mathrm{A} \beta_{42}$. Yakugaku Zasshi 131, 1843-1853. doi: 10.1248/yakushi.131.1843

Wilcock, D. M., and Griffin, W. S. (2013). Down's syndrome, neuroinflammation and Alzheimer neuropathogenesis. J. Neuroinflammation 10:84. doi: 10. 1186/1742-2094-10-84

Wright, A. L., Zinn, R., Hohensinn, B., Konen, L. M., Beynon, S. B., Tan, R. P., et al. (2013). Neuroinflammation an neuronal loss precede Abeta plaque deposition in the hAPP-J20 mouse model of Alzheimer's disease. PLoS One 8:e59586. doi: 10.1371/journal.pone.0059586

Yatin, S. M., Varadarajan, S., Link, C. D., and Butterfield, D. A. (1999). In vitro and in vivo oxidative stress associated with Alzheimer's amyloid beta-peptide (1-42). Neurobiol. Aging 20, 325-330; discussion 339-342.
Zilka, N., Kazmerova, Z., Jadhav, S., Neradil, P., Madari, A., Obetkova, D., et al. (2012). Who fans the flames of Alzheimer's disease brains? Misfolded tau on the crossroad of neurodegenerative and inflammatory pathways. J. Neuroinflammation 9:47. doi: 10.1186/1742-2094-9-47

Conflict of Interest Statement: The authors declare that the research was conducted in the absence of any commercial or financial relationships that could be construed as a potential conflict of interest.

Received: 27 October 2014; accepted: 02 December 2014; published online: 14 January 2015.

Citation: Joshi YB and Praticò D (2015) The 5-lipoxygenase pathway: oxidative and inflammatory contributions to the Alzheimer's disease phenotype. Front. Cell. Neurosci. 8:436. doi: 10.3389/fncel.2014.00436

This article was submitted to the journal Frontiers in Cellular Neuroscience.

Copyright (c) 2015 Joshi and Praticò. This is an open-access article distributed under the terms of the Creative Commons Attribution License (CC BY). The use, distribution and reproduction in other forums is permitted, provided the original author(s) or licensor are credited and that the original publication in this journal is cited, in accordance with accepted academic practice. No use, distribution or reproduction is permitted which does not comply with these terms. 